\begin{tabular}{|c|c|c|}
\hline & Int.J.Curr.Microbiol.App.Sci (2016) 5(10): 57-68 & \multirow{2}{*}{ 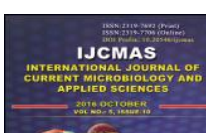 } \\
\hline & \multirow{4}{*}{$\begin{array}{l}\text { International Journal of Current Microbiology and Applied Sciences } \\
\text { ISSN: 2319-7706 Volume } 5 \text { Number } 10 \text { (2016) pp. 57-68 } \\
\text { Journal homepage: http://www.ijcmas.com }\end{array}$} & \\
\hline & & \\
\hline EXCELLENT & & \\
\hline PUBLISHERS & & wwwi.jicmas.com \\
\hline
\end{tabular}

Original Research Article

http://dx.doi.org/10.20546/ijcmas.2016.510.008

\title{
Antimicrobial Activity in vitro of Essential Oils from Oregano (Origanum compactum L.) and Thyme (Thymus vulgaris L.)
}

\author{
Teodora P. Popova* and Ralitsa Bankova \\ University of Forestry, Faculty of Veterinary Medicine, $10 \mathrm{Kl}$. Ohridski Blvd, \\ Sofia 1756, Bulgaria, GSM +359-886-53-15-50 \\ *Corresponding author
}

\begin{tabular}{|c|c|}
\hline & A B S T R A C T \\
\hline & \multirow{4}{*}{$\begin{array}{l}\text { The antimicrobial effect of essential oils from oregano (Origanum compactum L.) } \\
\text { and thyme (Thymus vulgaris L.) was investigated using the classical agar-gel } \\
\text { diffusion method. Pure cultures of } 20 \text { pathogenic strains were tested (by } 4 \text { strains of } \\
\text { Pseudomonas aeruginosa, Klebsiella pneumoniae, Pasteurella multocida, } \\
\text { Enterococcus faecalis and Candida albicans). Both oils exhibited significant in } \\
\text { vitro inhibitory activity against the tested bacterial and fungal strains. Thyme } \\
\text { essential oil showed a slightly higher antimicrobial activity as compared to that of } \\
\text { oregano when was applied in high final concentrations of } 1-4 \% \text {. The oregano oil, } \\
\text { however, showed higher inhibitory effect compared to that of thyme when was } \\
\text { administered at low concentrations between } 0,032 \% \text { and } 0,5 \% \text {. The antimicrobial } \\
\text { action of both oils was best expressed when were administered in a final } \\
\text { concentrations not lower than } 1 \% \text {, while concentrations below } 0,5 \% \text { were not } \\
\text { sufficient for expression of an effective action to most strains. Most pronounced } \\
\text { was the inhibitory effect of the essential oils from oregano and thyme against the } \\
\text { Gram-positive microorganisms tested - E. faecalis and C. albicans. From the tested } \\
\text { Gram-negative bacteria, the highest sensitivity to the oils showed the } P \text {. aeruginosa } \\
\text { strains. These results are very promising from a practical standpoint, since } \\
\text { enterococci, and P. aeruginosa distinguish with high resistance to antimicrobials } \\
\text { and rapid development of resistance to the antibiotics applied in infections with } \\
\text { their participation. High value in this aspect have and the results received for } C \text {. } \\
\text { albicans, as antifungals are too few and the treatment of mycosis is difficult and } \\
\text { prolonged. }\end{array}$} \\
\hline & \\
\hline & \\
\hline & \\
\hline
\end{tabular}

\section{Introduction}

Due to the increasing spread of polyresistant strains causing infections especially actual task of modern microbiology is demand for new natural or synthetic antimicrobials, non-toxic to animals and humans, which to inhibit effectively the multiplication of pathogenic microorganisms and to be suitable for the prophylaxis and treatment of various infections, as well as for use as safe food preservatives. There is evidence that essential oils of thyme, savory, mint, 
rosemary, yarrow, anise, bay leaf, coriander, eucalyptus and others have relatively high antimicrobial effect (Penalver et al., 2005; Lopez et al., 2007). In our country Nicheva et al., (1985) and Gurgulova et al., (1996) also found that essential oils of thyme, savory, mint, anise and eucalyptus have a high inhibitory activity against some pathogenic bacteria. When testing a standardized essential oils Malinova et al., (2003) found that strains of $B$. thuringiense are completely inhibited by oils of thyme, savory and rosemary, while those of $B$. cereus are more sensitive to oils of peppermint, catnip, yarrow, anise and eucalyptus and less to those of bay leaf and coriander. At the same time Stamatis et al., (2003) reported that essential oils from some herbs, including oregano (Origanum vulgare), have an inhibitory effect on the cause of stomach ulcers and gastritis in humans Helicobacter pylori. These results were confirmed by Brđanin et al., (2015). In Bulgaria Bankova et al., (2011) found in vitro antibacterial activity of essential oils of thyme, oregano, rosemary and sage against strains of E. coli, S. enterica and S. aureus, isolated from domestic animals. The highest antibacterial activity against the used strains have shown oils of oregano and thyme, especially on E. coli and S. aureus. One of the most promising is proved the essential oil of white rose (Rosa alba L.), which is produced quite recently only in Bulgaria. It exhibits a high inhibitory effect against Gram-positive bacteria, including E. faecalis and $S$. mutans, but its activity highest is against Gram-negative bacteria such as $A$. actinomycetemcomitan. The established radical-absorbing, antioxidant and antimicrobial activities of the essential oil of Rosa alba L., conditioned by its chemical composition (geraniol, monoterpenes, etc.) offer hope for its practical application as a new effective pharmaceutical antioxidant and antibacterial agent (Mileva et al., 2014).
According to Shohayeb et al., (2014) essential oil of Rosa damascena MILL also exhibits broad spectrum antimicrobial activity against Gram-positive ( $S$. aureus, $B$. subtilis, S. pyogenes), Gram negative (A. baumannii, $K$. pneumoniae), acid-resistant (M. phlei) bacteria and fungi (P. notatum, A. niger and C. albicans).

Some of these essential oils are proving promising ecological products of natural origin and an alternative to the currently used growth stimulants (Grela, 2000; Meriden, 2000; Ratcliff, 2000). Hopes are assigned to the application of plant extracts and essential oils based on chestnut, oregano, thyme, nettle and others. They have beneficial effects on productivity of animals and stimulate directly or indirectly their immune system, but also exhibit antimicrobial, fungicidal, antioxidant and other biological activities, especially the oil of oregano (Dorman and Deans, 2000; Corpet, 2000). There is no need of waiting period. Research in this direction become particularly relevant since 2006 , when it was introduced a ban on antibiotic growth promoters in the European Union because of the risk of resistance development in microorganisms. One of the promising in this respect is the essential oil of oregano (Origanum vulgare L.), which is mainly used as a spice in food and pharmaceutical industry. But in broiler chickens this oil shows good nutritive effect due to the contained therein biologically active substances: carvacrol, thymol, pinene, limonene and borneol. Carvacrol possesses antimicrobial, anticancer, antimutagenic, analgesic, antispasmodic, anti-parasitic, antiinsect and antihepatotoxic action (Donev, 2001; Baser, 2008). The essential oil of thyme also has a high content of phenols (thymol and carvacrol) and terpenes (paracimol and others). These ingredients and mainly thymol are known as strong 
antiseptics. In China, Xu et al., (2008) found an inhibitory effect of carvacrol and thymol against $E$. coli, due to the change in permeability and depolarization of the cytoplasmic membranes of the bacteria.

The trend of using essential oils from various herbs as a food additive in feed for different animals as an alternative to prophylactic use of antibiotics as growth promoters is based on the good results of the research in this direction. Study of Smink (2003) showed that the use of essential oil of oregano in pre starter diet of pigs plays a role of an antimicrobial growth promoter and has a beneficial effect on their health. In this aspect Ter Beek (2008) also reported good results using feed additives containing a mixture of essential oils of cinnamon, oregano, thyme, chilli and lemon. Significant reduction of the amount of pathogenic bacteria in the intestine of pigs was achieved, including ETEC. Dimitrova et al., (2004), Dimitrova (2009) and Yordanov et al., (2012) found a significant preventive effect of the preparation Bioxan-emulsum, containing an essential oil of oregano, used as a food additive for piglets. The reported prophylactic efficacy in terms of bacterial gastroenteritis and ileitis was similar to that of some nutritive antibiotics.

According to some studies, however, the composition, quality and content of essential oils found in plants, are subject to wide fluctuations and are influenced by various factors such as geographical and climatic conditions and growing conditions, drying and storage of herbal drugs (Cleff et al., 2010; Cleff et al., 2013). Also in literature lacks sufficient data on sensitivity to essential oils of some pathogenic bacteria rapidly developing resistance to antibiotics such as Pseudomonas aeruginosa, Klebsiella pneumoniae, Enterococcus faecalis, as well as fungi. In this respect, the aim of this study was to evaluate the inhibitory effect in vitro of essential oils of oregano and thyme on the development of pathogenic microorganisms from different groups.

\section{Materials and Methods}

\section{Microorganisms}

Pure cultures of 20 pathogenic strains of five different species were tested - 4 bacterial (by 4 strains of Pseudomonas aeruginosa, Klebsiella pneumoniae, Pasteurella multocida, Enterococcus, faecalis) and 4 strains of the oval fungus Candida albicans. Microorganisms were isolated in the Microbiological laboratory of Faculty of Veterinary Medicine at the University of Forestry from clinical specimens of pets (dogs) with chronic otitis and pyodermatitis, and Pasteurella multocida - from aviary bred pheasants died of cholera. The bacterial strains demonstrated in vitro poly-resistance to $\beta$-lactam, aminoglycoside and tetracycline antibiotics.

\section{Antibacterial means}

Essential oil $100 \%$ of oregano (Origanum compactum L.), produced by the company Pranarom International, Ghislenghien, Belgique (BE-BIO-01), importer - Floresans Ltd., Sofia, Bulgaria.

Essential oil $100 \%$ of thyme (Thymus vulgaris L.), produced by Riva Ltd., Plovdiv, Bulgaria.

Double-increasing dilutions $(4 \%, 2 \%, 1 \%$, $0.5 \%, 0.25 \%, 0.125 \%$ and $0.0625 \%$ ) of the oils were prepared in $96 \%$ ethanol, since essential oils are not water soluble.

Control: In determining the antimicrobial activity of the oils as the control was used the broad spectrum antibiotic thiamphenicol. 
The antimicrobial effect was tested using the classical agar-diffusion method of Bauer et al., (1966) intended for fast-growing under aerobic conditions microorganisms on Mueller Hinton agar with $\mathrm{pH} 7,2-7,4$ and layer thickness of $4 \mathrm{~mm}$. The preparations were administered by instillation of $0,1 \mathrm{ml}$ in wells with a diameter of $9 \mathrm{~mm}$. In parallel, a solution in physiological saline of the control antibiotic thiamphenicol was used by dropping in the wells of $0,1 \mathrm{ml}$ contained the standard concentration of $30 \mu \mathrm{g}$. The inoculation of the microbial suspensions at dose of $2.10^{6}$ cells $/ \mathrm{ml}$ was performed immediately before the introduction of the essential oils and the control in the wells. Then incubation for 2 hours at room temperature was carried out to evaporate the ethanol and for diffusion of the oils in the agar. Incubation was conducted at $35-37^{\circ} \mathrm{C}$ for 18-24 to 48 hours. Reporting of results was carried out by measuring the diameters of the inhibitory zones in millimeters accurate to the nearest whole millimeter including the wells diameter, with a transparent ruler and caliper on the outside of the plates bottoms.

The zones of inhibition were interpreted by the three-degrees system for categorizing of Bauer et al., (1966). According to this system of the Bauer-Kirby and NCCLS (1997, 1999), inhibitory effect of the oils is reported at zones $>12 \mathrm{~mm}$, and of the antibiotic - at > $17 \mathrm{~mm}$. The sensitivity of the test microorganisms to the oils was determined as follows: resistant (R) - at zones $<12 \mathrm{~mm}$, intermediate sensitive (I) - 13 to $16 \mathrm{~mm}$ and sensitive (S) - at zones >17 mm. For Thiamphenicol the relevant borders are: $\mathrm{R}$ $<12 \mathrm{~mm}, \mathrm{I}-13-17 \mathrm{~mm}$ and $\mathrm{S}->18 \mathrm{~mm}$.

Statistical analysis of the results was carried out by the classical method of StudentFisher.

\section{Results and Discussion}

The summarized results of the studies of the effect of the essential oils of both herbs in concentrations of 1,2 and $4 \%$ for the used bacterial and fungal strains are presented in Table 1. Some of them can be seen and in Figures 1-3.

As can be seen from the data in the table, when were used in such concentrations both essential oils exhibited significant antimicrobial activity against all tested microorganisms.

Pooled results for the mean arithmetic diameters of the zones without growth calculated for all tested by us microorganisms at the use of the oil of thyme in a final concentration of $4 \%$ statistically significantly exceed those of the control antibiotic thiamphenicol $(\mathrm{P}<0,05)$, but in the smaller concentrations tested the differences were not significant $(\mathrm{P}>0,05)$ except for $C$. albicans. Most pronounced was the inhibitory effect of the essential oils from oregano and thyme against Gram-positive microorganisms - E. faecalis and pathogenic fungi from the species $C$. albicans. The reported inhibitory zones for these in both oils in these concentrations were greater than the areas of application of the control broad spectrum antibiotic thiamphenicol, although the differences with most bacterial species tested were not statistically significant $(\mathrm{P}>0,05)$. Only in E. faecalis the inhibition zones of the oil of thyme in concentration of $4 \%$ were significantly higher than those of the antibiotic $(\mathrm{P}<0,01)$. In $C$. albicans the inhibition zones at application of the two essential oils in concentrations of 1,2 and $4 \%$ were significantly higher than the inhibition zones of thiamphenicol $(\mathrm{P}<0,001)$. This is explained by the primary resistance of fungi to antibiotics, but 
additional emphasizes their high sensitivity to these essential oils. Of the tested Gramnegative bacteria highest sensitivity to the oils showed the strains of $P$. aeruginosa.

The data in Table 1 also show that the essential oil of thyme exhibited stronger antimicrobial activity compared with the oil of oregano when testing in high concentrations of 1,2 and $4 \%$. The differences in the effect between the two oils, however, in all tested microorganisms were not statistically significant $(\mathrm{P}>0.05)$.

From the data presented in the table and in figure 1 is impressive the high susceptibility of $P$. aeruginosa to both essential oils, superior to this to thiamphenicol. The antimicrobial effect of the essential oils from oregano and thyme against $P$. aeruginosa was significant and was not inferior to that of the control broad spectrum antibiotic, and even exceeded it. Thyme essential oil exhibited a slightly higher antimicrobial activity against most tested strains of $P$. aeruginosa compared to that of oregano.

The two essential oils showed significant inhibitory activity against the tested strains of $K$. pneumoniae. The diameters of the zones of growth inhibition were similar to those of the broad spectrum antibiotic thiamphenicol. When was used in concentrations between $1 \%$ and $4 \%$, the essential oil of thyme exhibited a slightly higher antimicrobial activity against the strains of $K$. pneumoniae when compared to that of oregano, similar in $P$. aeruginosa. The data in the table also show that the antibacterial action of the oils was especially high at their application in concentrations of $4 \%$ and $2 \%$ and in these cases it was superior to that of thiamphenicol Figure 2 illustrates the high sensitivity of $K$. pneumoniae (strain № 6) to the essential oil of oregano, as well as to that of thyme, especially when were applied in the highest tested concentrations of $4 \%$ and $2 \%$.

The results in Table 1 also show the high inhibitory activity of both essential oils against the tested strains of $P$. multocida. The effect of the oils and on this bacterial species was highest at their application in concentrations of $4 \%$ and $2 \%$.

From data presented in Table 1 and in Figure 3 is seen the high sensitivity of $E$. faecalis to both tested oils. The antimicrobial effect of the essential oils from oregano and thyme against $E$. faecalis was significant and was not inferior to that of the broad spectrum control antibiotic. In concentrations between $1 \%$ and $4 \%$ the essential oil of thyme exhibited a slightly higher antimicrobial activity against most tested strains in comparison with that of oregano.

Figure 3 demonstrates the inhibitory activity of the test oils against E. faecalis (strain № 16). It can be seen that the more pronounced was the effect of oregano oil, administered in concentrations of $1 \%, 2 \%$ and $4 \%$. The antimicrobial activity of thyme oil was well expressed in concentrations of $2 \%$ and $4 \%$.

Table 2 shows the summarized results of testing the sensitivity of the same microorganisms to the essential oils from oregano and thyme, applied in smaller final concentrations in the range between $0,032 \%$ and $0,5 \%$. In these low concentrations, however, the effect of oil of thyme was weaker than that of oil of oregano. The inhibition zones in all tested strains were smaller than those of thiamphenicol, as the differences were statistically significant in $P$. aeruginosa, $K$. pneumoniae and $E$. faecalis $(\mathrm{P}<0,05$ at the oil of oregano, and $\mathrm{P}<0,01$ at this of thyme), but not in $P$. 
multocida and $C$. albicans $(\mathrm{P}>0,05)$. The oil of oregano showed higher antimicrobial effect when was applied in these low concentrations. The inhibitory areas thereof were larger than those of oil of thyme $(\mathrm{P}>0,05)$. The strains of $P$. multocida showed the highest sensitivity to the oil of oregano administered in concentrations ranging between $0.032 \%$ and $0.5 \%$, such as enterococci, which were sensitive at a high degree to concentrations of 0,5 and $0,25 \%$.

From the results presented in the table also makes an impression the high inhibitory activity of both essential oils to the tested strains of $C$. albicans. The antimycotic effect of essential oils from oregano and thyme was well expressed when were applied in final concentrations of no more than $1 \%$, but even in concentrations below $0,5 \%$ the oils had such an effect, especially that of oregano.

From the data presented in the tables it is seen that the inhibitory effect of the two essential oils against most of the tested microorganisms was most pronounced when were administered in a final concentrations not lower than $1 \%$. At concentrations below $0,5 \%$ the in vitro effect against the tested pathogenic polyresistant bacteria was insignificant.

The results of the present studies categorically confirm the possibilities for successful practical application of essential oils from oregano and thyme as natural therapeutic and prophylactic agents with antibacterial and antifungal effect. The present results are very promising in view of the practical application of these essential oils, as the tested by us pathogenic microorganisms, especially enterococci, $P$. aeruginosa and $K$. pneumoniae, distinguish by poly-resistance to antimicrobials and rapid development of resistance to the antibiotics, applied in infections with their participation. For this reason the infections, caused by these, are persistent and difficult to treat.

The present study results are in accordance with those of other authors in our country as Nicheva et al., (1985), Gurgulova et al., (1996), Malinova et al., (2003) in testing the antimicrobial effect of essential oils of savory, mint, anise, eucalyptus and thyme. They examined bacteria from other species and reported a relatively high activity against certain pathogenic bacteria, as thyme oil is pointed out as a particularly effective against Gram-positive species such as B. thuringiense.

In a study of the antibacterial effectiveness of essential oils from oregano, thyme and cinnamon against some pathogenic microorganisms (E. coli, P. aeruginosa, $S$. Choleraesuis, $S$. aureus, $B$. cereus and others) Lopez et al., (2007) also concluded that the minimum inhibitory concentrations of oregano oil for these bacteria are lower compared to those of other oils and pointed out the high effect of oil of oregano. In studies of 5 essential oils against isolated from poultry and pigs strains of E. coli (including ETEC) and of $S$. enterica, Penalver et al., (2005) also found that oil of oregano (Origanum vulgare L.) exhibits strong antimicrobial activity against $S$. enterica. Derwich et al., (2010) established a significant inhibitory activity of oregano oil originating from Morocco, against some significant bacteria such as $S$. aureus, $B$. subtilis, L. monocytogenes, C. botulinum, $C$. perfringens and $E$. coli and weak activity against $P$. aeruginosa, $S$. Typhimurium, $C$. jejuni and $V$. cholerae. Our results largely correspond to those received by Bankova et al., (2011). When comparing the antibacterial activity in vitro of Bulgarian essential oils of rosemary (Rosmarinus 
officinalis), sage (Salvia sclarea), thyme (Thymus vulgaris) and oregano (Origanum vulgare) against strains of $E$. coli, Salmonella spp. and $S$. aureus, isolated from livestock, they also established a high inhibitory effect of essential oils of thyme and oregano, especially of the oregano oil and particularly against $E$. coli and $S$. aureus. This activity has been followed by the thyme oil against E. coli, S. aureus and Salmonella spp. In Serbia, Levic et al., (2011) established a high antibacterial activity of essential oils from oregano $(O$. vulgare), wild thyme (Thymus serpyllum) and thyme (T. vulgaris) against laboratory control strains of E. coli, S. Choleraesuis, $P$. mirabilis, $S$. aureus and E. faecalis. The essential oil of oregano have shown the highest antimicrobial effectiveness, especially against Gram-negative bacteria. According Bouhdid et al., (2008) the essential oil from Origanum compactum has good antioxidant effect and a high antibacterial activity in vitro against standard reference strains of $E$. coli, $P$. mirabilis, $S$. aureus, L. monocytogenes, $L$. innocua, E. faecium and B. subtilis. Species of the genus Pseudomonas ( $P$. aeruginosa and $P$. fluorescens) have shown resistance to oil concentrations below $1 \%$, which is consistent with the results of our studies. The authors explain this high activity with the phenolic compounds, contained in the oil of oregano.

The established as a result of our research high sensitivity of $P$. aeruginosa and $E$. faecalis to the action of both oils is particularly promising from a practical point of view having in mind the rapid development of antibiotic resistance in these bacteria and the widespread of polyresistant strains. High value in this aspect have and the results for $C$. albicans, as the antifungals are too few and the treatment of mycosis is difficult and prolonged.

Table.1 Inhibitory effect of the essential oils of Oregano $(\mathrm{O})$ and Thyme $(\mathrm{T})$ in concentrations from $1 \%$ to $4 \%$ on pathogenic microorganisms in the agar diffusion method

\begin{tabular}{|c|c|c|c|c|c|c|c|c|}
\hline \multirow{3}{*}{$\begin{array}{l}\text { Microor- } \\
\text { ganisms }\end{array}$} & \multirow{3}{*}{$\begin{array}{l}\text { Number } \\
\text { of strains } \\
\text { tested }\end{array}$} & \multicolumn{7}{|c|}{ Inhibition zones in mm } \\
\hline & & \multicolumn{2}{|c|}{$4 \%$} & \multicolumn{2}{|c|}{$2 \%$} & \multicolumn{2}{|c|}{$1 \%$} & \multirow{2}{*}{$\begin{array}{l}\text { Th } \\
\text { C }\end{array}$} \\
\hline & & $\mathbf{O}$ & $\mathbf{T}$ & $\mathbf{O}$ & $\mathbf{T}$ & $\mathbf{O}$ & $\mathbf{T}$ & \\
\hline $\begin{array}{l}\text { Pseudomonas } \\
\text { aeruginosa }\end{array}$ & 4 & $\begin{array}{l}36,0 \\
\pm 3,54\end{array}$ & $\begin{array}{l}38,5 \\
\pm 12,5\end{array}$ & $\begin{array}{l}31,5 \\
\pm 8,05\end{array}$ & $\begin{array}{l}32,5 \\
\pm 7,63\end{array}$ & $\begin{array}{l}27,0 \\
\pm 6,04\end{array}$ & $\begin{array}{l}28,8 \\
\pm 9,05\end{array}$ & $\begin{array}{l}29,25 \\
\pm 5,76\end{array}$ \\
\hline $\begin{array}{l}\text { Klebsiella } \\
\text { pneumoniae }\end{array}$ & 4 & $\begin{array}{l}33,25 \\
\pm 4,32\end{array}$ & $\begin{array}{l}36,0 \\
\pm 5,83\end{array}$ & $\begin{array}{l}26,5 \\
\pm 2,06\end{array}$ & $\begin{array}{l}30,5 \\
\pm 7,92\end{array}$ & $\begin{array}{l}22,75 \\
\pm 3,83\end{array}$ & $\begin{array}{l}28,0 \\
\pm 8,57\end{array}$ & $\begin{array}{l}29,75 \\
\pm 3,83\end{array}$ \\
\hline $\begin{array}{l}\text { Pasteurella } \\
\text { multocida }\end{array}$ & 4 & $\begin{array}{l}34,5 \\
\pm 4,55\end{array}$ & $\begin{array}{l}36,5 \\
\pm 4,97\end{array}$ & $\begin{array}{l}30,25 \\
\pm 5,93\end{array}$ & $\begin{array}{l}34,0 \\
\pm 5,78\end{array}$ & $\begin{array}{l}28,0 \\
\pm 4,47\end{array}$ & $\begin{array}{l}24,0 \\
\pm 2,45\end{array}$ & $\begin{array}{l}33,25 \\
\pm 4,43\end{array}$ \\
\hline $\begin{array}{l}\text { Enterococcus } \\
\text { faecalis }\end{array}$ & 4 & $\begin{array}{l}38,5 \\
\pm 7,53\end{array}$ & $\begin{array}{l}46 \\
\pm 3,16\end{array}$ & $\begin{array}{l}35,75 \\
\pm 7,56\end{array}$ & $\begin{array}{l}36,75 \\
\pm 7,79\end{array}$ & $\begin{array}{l}27,75 \\
\pm 9,55\end{array}$ & $\begin{array}{l}28,0 \\
\pm 2,0\end{array}$ & $\begin{array}{l}31,75 \\
\pm 4,11\end{array}$ \\
\hline $\begin{array}{l}\text { Candida } \\
\text { albicans }\end{array}$ & 4 & $\begin{array}{l}34 \\
\pm 6,67\end{array}$ & $\begin{array}{l}43,5 \\
\pm 6,06\end{array}$ & $\begin{array}{l}26,25 \\
\pm 3,34\end{array}$ & $\begin{array}{l}37,0 \\
\pm 2,55\end{array}$ & $\begin{array}{l}23,75 \\
\pm 4,82\end{array}$ & $\begin{array}{l}29,75 \\
\pm 3,34\end{array}$ & $\begin{array}{l}11,25 \\
\pm 0,51\end{array}$ \\
\hline Total & 20 & $\begin{array}{l}35,25 \\
+1,86 \\
\end{array}$ & $\begin{array}{l}40,1 \\
+3,97\end{array}$ & $\begin{array}{l}30,0 \\
\pm 3,51\end{array}$ & $\begin{array}{l}34,15 \\
+2,49\end{array}$ & $\begin{array}{l}25,85 \\
+2,17\end{array}$ & $\begin{array}{l}27,55 \\
+1,9\end{array}$ & $\begin{array}{l}27,05 \\
\pm 3,98\end{array}$ \\
\hline
\end{tabular}


Table.2 Inhibitory effect of the essential oils of Oregano (O) and Thyme (T) in concentrations from $0,032 \%$ to $0,5 \%$ on pathogenic microorganisms in the agar diffusion method

\begin{tabular}{|c|c|c|c|c|c|c|c|c|c|c|c|}
\hline \multirow{3}{*}{$\begin{array}{l}\text { Microor- } \\
\text { ganisms }\end{array}$} & \multirow{3}{*}{$\begin{array}{l}\text { Number } \\
\text { of strains } \\
\text { tested }\end{array}$} & \multicolumn{10}{|c|}{ Inhibition zones in $\mathrm{mm}$} \\
\hline & & \multicolumn{2}{|c|}{$0,5 \%$} & \multicolumn{2}{|c|}{$\mathbf{0 , 2 5 \%}$} & \multicolumn{2}{|c|}{$\mathbf{0 , 1 2 5 \%}$} & \multicolumn{2}{|c|}{$0,0625 \%$} & \multicolumn{2}{|c|}{$\mathbf{0 , 0 3 2 \%}$} \\
\hline & & $\mathbf{O}$ & $\mathbf{T}$ & $\mathbf{O}$ & $\mathbf{T}$ & $\mathbf{O}$ & $\mathbf{T}$ & $\mathbf{O}$ & $\mathbf{T}$ & $\mathbf{O}$ & $\mathbf{T}$ \\
\hline \multirow{2}{*}{$\begin{array}{l}\text { Pseudomonas } \\
\text { aeruginosa }\end{array}$} & 4 & 11,75 & $11,($ & 10,75 & 11,25 & & & 0,5 & 10,75 & 10,00 & 10,00 \\
\hline & & & $\pm 1,0$ & $\pm 0,4$ & $\pm 0,4$ & & $\pm 0,5$ & $\pm 0,5$ &, \pm 43 & $\pm 0,0$ & $\pm 0,7$ \\
\hline \multirow{2}{*}{$\begin{array}{l}\text { Klebsiella } \\
\text { pneumoniae }\end{array}$} & 4 & 14, & 10,7 & & 10,0 & & & 10,67 & 10,33 & 10,33 & 10,33 \\
\hline & & $\pm 2,62$ & $\pm 0,94$ & $\pm 0,81$ & $\pm 1,41$ & \pm 0 & $\pm 0,47$ & $\pm 0,47$ & $\pm 0,47$ & $\pm 0,92$ & $\pm 0,47$ \\
\hline \multirow{2}{*}{$\begin{array}{l}\text { Pasteurella } \\
\text { multocida }\end{array}$} & 4 & 18,25 & 12,0 & 17,25 & 12,0 & 17 & 12,25 & 17,0 & 11,25 & 17,0 & 11,8 \\
\hline & & $\pm 9,7$ & $\pm 1,41$ & \pm 10 & $\pm 1,87$ & $\pm 10,1:$ & \pm 11 & $\pm 10,4$ & $\pm 1,64$ & $\pm 10,4$ & $\pm 1,48$ \\
\hline \multirow{6}{*}{$\begin{array}{l}\text { Enterococcu } \\
\text { faecalis } \\
\text { Candida } \\
\text { albicans } \\
\text { Total }\end{array}$} & 4 & 17,5 & 11,7 & 15,0 & 11,5 & & 11,0 & 14,25 & 11,0 & 11,25 & 10,5 \\
\hline & & & & & & & & & \pm 0 & & $\pm 0,5$ \\
\hline & 4 & 13,75 & 11,75 & 13,5 & 12,25 & 13,5 & 12,25 & 13,25 & 11,5 & 12,75 & 10,5 \\
\hline & & $\pm 1,08$ & $\pm 3,0$ & \pm 0 & $\pm 2,77$ & $\pm 0,5$ & \pm 2 & $\pm 1,3$ & $\pm 2,29$ & $\pm 1,3$ & $\pm 1,5$ \\
\hline & 20 & 15,12 & 11,44 & 13,7 & 11,4 & 13,1 & 11,27 & 13,3 & 10,97 & 12,27 & 10,63 \\
\hline & & $\pm 2,42$ & $\pm 0,5$ & $\pm 2,28$ & $\pm 0,78$ & $\pm 2,6$ & $\pm 0,83$ & $\pm 2,42$ & $\pm 0,4$ & $\pm 2,55$ & $\pm 0,61$ \\
\hline
\end{tabular}

$O$ - essential oil of oregano; $T$ - essential oil of thyme

Fig.1 Antibacterial effect of essential oil of Oregano (left) and essential oil of thyme (right) in concentrations of $1 \%, 2 \%$ and $4 \%$, and of the control antibiotic thiamphenicol against $P$. aeruginosa (strain № 4)

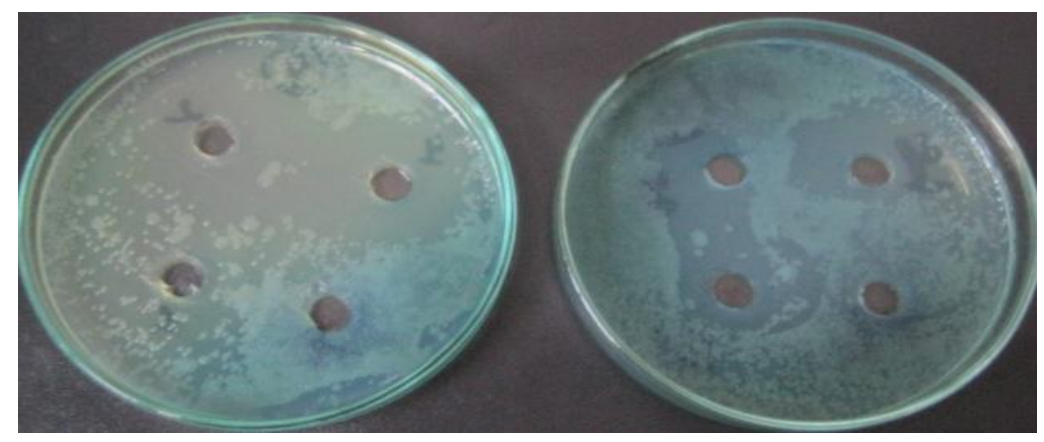

Fig.2 Antibacterial effect of essential oil of Oregano (left) and essential oil of thyme (right) in concentrations of $1 \%, 2 \%$ and $4 \%$, and of the control antibiotic thiamphenicol against $K$. pneumoniae (strain № 6)

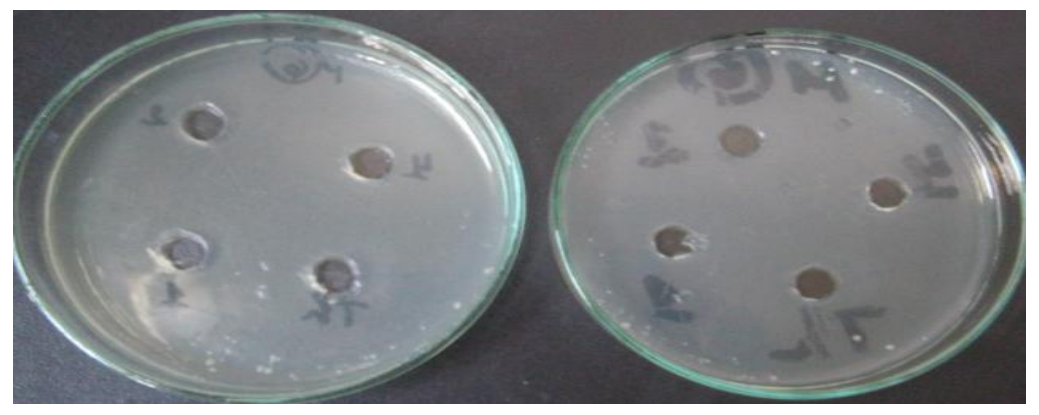


Fig.3 Antibacterial effect of essential oil of Oregano (left) and essential oil of thyme (right) in concentrations of $1 \%, 2 \%$ and $4 \%$, and of the control antibiotic thiamphenicol against

Enterococcus faecalis (strain № 16)

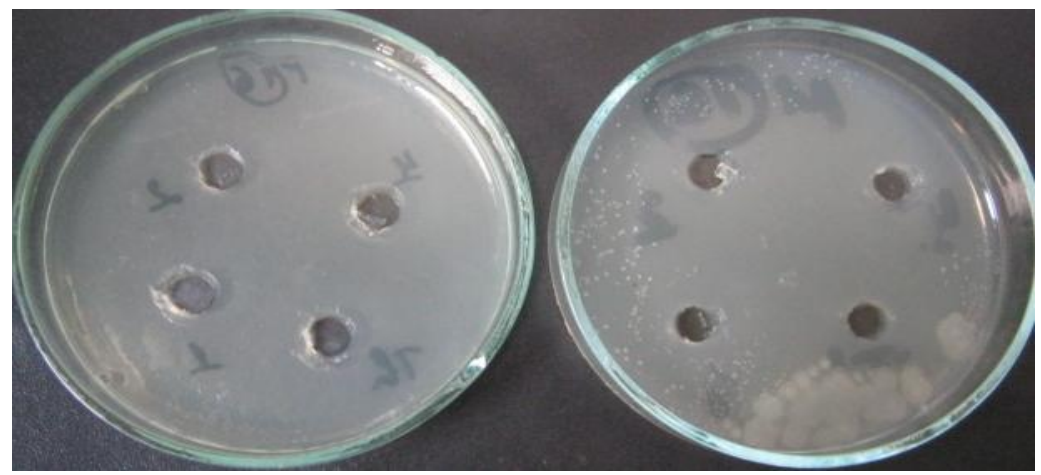

The results obtained by the current research reveal perspectives for use of essential oils of oregano and thyme for the local treatment of bacterial and fungal infections after appropriate clinical trials, since they are effective in vitro and safe for patients and for the environment. In recent years, other authors such as Mileva et al., (2014), Shohayeb et al., (2014), Shahnama et al., (2015) also emphasized prospects in the use of essential oils of some plants for the development of drugs for treatment of bacterial infections associated with pathogens such as E. faecalis, S. aureus, $S$. agalactiae, B. cereus, L. monocytogenes, E. coli, K. pneumoniae, $P$. mirabilis, S. enterica, $P$. aeruginosa, and of fungal infections (Cleff et al., 2013; Shohayeb et al., 2014).

Busatta et al., (2007), Bošković et al., (2013) and Macwan et al., (2016) pointed out that due to their antimicrobial properties, some spices and herbs, which are added to foods for the people to alter or improve their taste, can also increase their shelf life. These ingredients contribute to self-defense of the plants against infectious microorganisms. Thus the use of essential oils of herbs and spices could be a better choice than synthetic chemical additives, particularly for the production of the increasingly popular organic and natural foods. The present study results are in support of this view.

The established by us significant broad spectrum antimicrobial activity of the essential oils from oregano and thyme, which is manifested even against poly-resistant to antimicrobials bacteria such as $P$. aeruginosa and E. faecalis, and against fungi is a prerequisite for successful use of these oils not only as an alternative to the nutrition antibiotics in animal feed but also in the pharmaceutical and cosmetic industries, as well as like natural preservatives in the food industry.

In our opinion, easily developing of resistance of microorganisms to them should not be expected because of their complex chemical composition representing a combination of different ingredients with antimicrobial effect. It is known that upon administration of one antimicrobial agent (antibiotic or chemical compound) many microorganisms easy develop and spread resistance to it. When is used a combination of antimicrobial drugs, however, this is not observed or is an exception. In this connection it should be expected that at use of substances with many antimicrobial ingredients such as essential oils, the opportunities for development of resistance are minimized. 
In conclusion, the essential oils of oregano and thyme demonstrate in vitro pronounced inhibitory effect against clinical strains of Pseudomonas aeruginosa, Klebsiella pneumoniae, Pasteurella multocida и Enterococcus faecalis, comparable to that of the broad spectrum antibiotic thiamphenicol. They show and well expressed antifungal activity against Candida albicans. The antimicrobial effect of the essential oils from oregano and thyme is high in concentrations $2-4 \%$, good in $1 \%$ and significantly decreases in lower concentrations.

\section{References}

Bankova, R., K. Gurgulova, and Yordanov, S. 2011. In vitro study of the antibacterial activity of some essential oils against strains of pathogenic bacteria isolated from domestic animals. Int. Sc. Conference "Traditions and Modernity in veterinary medicine", 372-378 (In Bulgarian).

Baser, Can, K.H. 2008. Biological and pharmacological activities of carvacrol and carvacrol bearing essential oils. Curr. Pharma. Design., 14(29): 31063119.

Bauer, A.W., W.M. Kirby, J.C. Cherris, and Truck, M. 1966. Antibiotic susceptibility testing by a standardized single disk method. The Am. J. Clin. Pathol., 45(4): 493 - 496.

Bošković, M., Ž.M. Baltić, J. Ivanović, J. Đurić, J. Lončina, M. Dokmanović, and Marković, R. 2013. Use of essential oils in order to prevent foodborne illnesses caused by pathogens in meat. Tehnologija mesa, 54: 14-20.

Bouhdid, S., S.N. Skali, M. Idaomar, A. Zhiri, D. Baudoux, M. Amensour, and Abrini, J. 2008. Antibacterial and antioxidant activities of Origanum compactum essential oil. African $J$.
Biotechnol., 7(10): 1563-1570.

Brđanin, S., N. Bogdanović, M. Kolundžić, M. Milenković, N. Golić, M. Kojić, and Kundaković, T. 2015. Antimicrobial activity of Oregano (Origanum vulgare L.) and Basil (Ocimum basilicum L.) extracts. Adv. Technol., 4(2): 05-10.

Busatta, C., A. Mossi, M.R. Rodrigues, R. Cansian, and Oliveira, J. 2007. Evaluation of Origanum vulgare essential oil as antimicrobial agent in sausage. Brazilian J. Microbiol., 38: 610-616.

Cleff, M., A. Meinerz, M. Xavier, L. Schuch, M.C. Meireles, M.R. Rodrigues, and. Braga de Mello, J.R. 2010. In vitro activity of Origanum vulgare essential oil against Candida species. Brazilian J. Microbiol., 41: 116-123.

Cleff, M., I. Madrid, A. Meinerz, M.C. Meireles, J.R. Braga de Mello, M.R. Rodrigues, and Escareño, J.J. 2013. Essential oils against Candida spp: in vitro antifungal activity of Origanum vulgare. African J. Microbiol. Res., 7(20): 2245-2250.

Corpet, D.E. 2000. Mechanism of antimicrobial growth promoters used in animal feed. Rev. Med. Vet., 151(2): 99-104 (in French).

Derwich, E., Z. Benziane, A. Manar, A. Boukir, and Taouil, R. 2010. Phytochemical analysis and in vitro antibacterial activity of the essential oil of Origanum vulgare from Morocco. American-Eurasian J. Scientific Res., 5(2): 120-129.

Dimitrova, A. 2009. Bacterial infections in farms affected by PRRS. PhD Thesis, NDRVMI, Sofia (In Bulgarian).

Dimitrova, A., R. Bankova, S. Yordanov, S. Mavrikova, and Petlov, D. 2004. Comparative testing of Bioxanemulsum for prevention of bacterial enteritis in piglets. Vet. Collection, 
112(7/8): 16-21 (In Bulgarian).

Donev, B. 2001. Orego-stim - the new future. Poultry. 3, 20-21 (In Bulgarian).

Dorman, H.I., and Deans, S. 2000. Antimicrobial agents from tile oils. $J$. Appl. Microbiol., 88: 308-316.

Grela, E.R. 2000. Influence of herbs mixture in pig feeding of performance and some lipid parameters in blood and backfat. Annals Univ. Maria Curie, Lubline, 18, 243-250.

Gurgulova, K., I. Vassileva, M. Bonovska, and Todorov, D. 1996. Antibacterial activity of essential oils on $B$. alvei and $B$. paraalvei. RVS-Varna, Summaries of ASC, p. 63 (In Bulgarian).

Levic, J., I. Čabarkapa, G. Todorović, S. Pavkov, S. Sredanović, T. CoghillGalonja, and Kostadinović, L. 2011. In vitro antibacterial activity of essential oils from plant family Lamiaceae. Romanian Biotechnol. Lett., 16(2): 6034 - 6041.

Lopez, P., C., Sanchez, R. Batlle, and Nerin, C. 2007. Vapor-phase activities of cinnamon, thyme and oregano oils and key constituents against food borne microorganisms. J. Agri. Food Chem., 55(11): 4348-4356.

Macwan, S.R., B.K. Dabhi, K.D. Aparnathi, and Prajapati, J.B. 2016. Essential oils of herbs and spices: their antimicrobial activity and application in preservation of food. Int. J. Curr. Microbiol. App. Sci., 5(5): 885-901.

Malinova, K., K. Gurgulova, I. Vasileva, and Korudzhiyski, N. 2003. Sensitivity of $B$. cereus and $B$. thuringensis, isolated from silkworms to some essential oils. ISC "80 Years University of Forestry", Proceedings, Vet. Med., Section, Sofia, pp. 90-93 (In Bulgarian).

Meriden. 2000. Meriden animal Health, Orego-stim, Feed Additive.

Mileva, M.M., V.K. Kusovski, D.S. Krastev, A.M. Dobreva, and Galabov, A.S.
2014. Chemical composition, in vitro antiradical and antimicrobial activities of Bulgarian Rosa alba L. essential oil against some oral pathogens. Int. J. Curr. Microbiol. App. Sci., 3(7): 11-20.

NCCLS. 1997. Performance Standards for Antimicrobial Disk Susceptibility Tests. 1997. 6-th ed. Approved Standard. NCCLS Document M2 - A6, 17: 1 .

NCCLS. 1999. Performance Standards for Antimicrobial Susceptibility Testing: Ninths Informational Supplement. NCCLS Document M100 - S9, 18, 1.

Nicheva, L., I. Peshkov, H. Manev, and Apostolova, B. 1985. Antibacterial activity of some essential oils against listeria. IV Congress of Microbiology, Varna, V. I, 583-586 (In Bulgarian).

Penalver, P., B. Huerta, C. Borge, R. Astorga, R. Romero, and Perea, A. 2005. Antimicrobial activity of five essential oils against origin strains of the Enterobacteriaceae family. APMIS, 113(1): 1-6.

Ratcliff, J. 2000. Antibiotic Bans-A European Perspective Proceed of the AFMA Symposium on Improving Animal Performance through Nutrition. Pretoria, South Africa, p.128.

Shahnama, M., S. Azami, and Mohammadhosseini, $\quad$ M. 2015. Characterization of the essential oil and evaluation of antibacterial activity of methanolic extract of Stachys lavandulifolia Vahl. Int. J. Curr. Microbiol. App. Sci., 4(3): 275-283.

Shohayeb, M., El-S, S., Abdel-Hameed, S.A., Bazaid, and Maghrabi, I. 2014. Antibacterial and antifungal activity of Rosa damascena MILL essential oil, different extracts of rose petals. Global J. Pharmacol., 8(1): 01-07.

Smink, W. 2003. Oregano oil boost. Pig Progress, 19(3): 24-25. 
Stamatis, G., P. Kyriazopoulos, S. Golegou, A. Basayiannis, S. Skaltsas, and Skaltsa, H. 2003. In vitro anti-Helicobacter pylori activity of Greek herbal medicines. $J$. Ethnopharmacol., 88(2/3): 175-179.

Ter Beek, V. 2008. Improved gut health by use of oil blend. Pig Progress, 24(2): 22-23.

Xu, J., F. Zhou, b.P. Ji, R.S. Pei, and Xu, N. 2008. The antibacterial mechanism of carvacrol and thymol against

Escherichia coli. Lett. Appl. Microbiol., 47(3): 174-179.

Yordanov, S., R. Pepovich, A. Ivanova, R. Bankova, M. Dragoycheva, and Ganchev, K. 2012. Scheme of control of ileitis in pigs grown in industrial and semi-industrial swine-breeding conditions. Int. Sc. Conference "Traditions and Modernity in veterinary medicine", 221-230 (In Bulgarian).

\section{How to cite this article:}

Teodora P. Popova and Ralitsa Bankova. 2016. Antimicrobial Activity in vitro of Essential Oils from Oregano (Origanum compactum L.) and Thyme (Thymus vulgaris L.). Int.J.Curr.Microbiol.App.Sci. 5(10): 57-68. doi: http://dx.doi.org/10.20546/ijcmas.2016.510.008 